PHYSICAL REVIEW X 7, 029902 (2017)

\title{
Publisher's Note: Hot Electrons Regain Coherence in Semiconducting Nanowires [Phys. Rev. X 7, 021016 (2017)]
}

Jonathan Reiner, Abhay Kumar Nayak, Nurit Avraham, Andrew Norris, Binghai Yan, Ion Cosma Fulga, Jung-Hyun Kang, Torsten Karzig, Hadas Shtrikman, and Haim Beidenkopf

(Received 19 May 2017; published 26 May 2017)

DOI: 10.1103/PhysRevX.7.029902

This paper was published online on 5 May 2017 with an error in the author list. The eighth author's name should read as "Torsten Karzig." The author name has been corrected as of 22 May 2017.

Published by the American Physical Society under the terms of the Creative Commons Attribution 4.0 International license. Further distribution of this work must maintain attribution to the author(s) and the published articles title, journal citation, and DOI. 